\title{
PREVENTION OF SYRINGE-TRANSMITTED HEPATITIS
}

for gonorrhoea, as well as after intramuscular penicillin injections for syphilis. Moreover, the syringe transmission of infection is not confined to the venereal disease clinic. Thus homologous serum jaundice has been reported after gold injections for rheumatoid arthritis (Hartfall, Garland and Goldie), after the routine withdrawal of blood for erythrocyte sedimentation tests in sanatorium patients (Sheehan), and after the administration of intravenous anaesthetics (Darmady and Hardwick); malarial infection has been transmitted among patients receiving intravenous injections (Salvarsan Committee's second report). It will be appreciated, therefore, that a satisfactory syringe technique has wide applications not only in venereal diseases clinics but elsewhere also.

The Medical Research Council's recent report, The Sterilization, Use and Care of Syringes, recommends the sterilization of needles and syringes in the hot-air oven or the autoclave and the use of single-dose containers for injection fluids. These methods were used in the injection technique developed by Salaman and his colleagues (1944). For mass injections the Council recommends a team of four, which is the number required to operate the technique described by Salaman and his co-workers. These methods demand optimal conditions, whereas it would appear that the Preston technique achieves maximal results with a minimum of personnel and equipment.

\section{Recommendations}

In order to reduce the risk of syringe transmission of blood from one patient to another, it is recommended that the following precautions should be observed.

(1) Specimens of blood for serological or other tests should be collected with a needle and tube only. If syringes are used, they should be reserved solely for this purpose.

(2) Syringes used for penicillin or other compounds given by the intramuscular route should be of not more than 5 cubic centimetres' capacity; they should not be used for the collection of blood or for intravenous medication.

To eliminate the possibility of syringe-transmitted infection, the careful operation of an injection technique similar to, or observing the principles of, the Preston technique, is recommended.

\section{Summary}

The development and operation of a syringe technique designed to eliminate the transmission of blood from one patient to another in a large syphilis clinic is described. The results obtained, together with controls, indicate that hepatitis complicating arsenotherapy is usually an example of homologous serum jaundice and is readily preventable.

\section{REFERENCES}

Beattie, J. (1943) Brit. J. vener. Dis., 19, 62.

- and Marshall, J. (1944) Brit. med. J., 2, 651.

Bigger, J. W. (1943) Lancet, 1, 457.

Darmady, E. M. and Hardwick, C. (1945) Lancet, 2, 106.

Hartfall, S. J., Garland, H. G., and Goldie, W. (1937) Lancet, 2, 838.

MacCallum, F. O. (1943) Brit. J. vener. Dis., 19, 63.

Marshall, J. (1943) Brit. J. vener. Dis., 19, 52.

Medical Research Council (1945) War Memorandum No. 15, The Sterilization, Use and Care of Syringes, H.M. Stationery Office, London.

Salaman, M. H., King, A. J., Williams, D. I., and Nicol, C. S. (1944) Lancet, $2,7$.

Salvarsan Committee (1922) Spec. Rep. Ser. Med. res. Coun., Lond., No. 66.

Sheehan, H. L. (1944) Lancet, $2,8$.

Special Article (1945) Lancet, 2, 116.

\section{DISCUSSION ON THE PRECEDING PAPER}

Air-Cdre. G. L. M. McElligott (the President) said that Maj. Laird's paper had been most carefully and convincingly presented. Few of them would quarrel with the statement that the majority of these cases of post-arsphenamine jaundice were, in fact, of infective origin. With regard to penicillin, he had had reported to him, before May 1945, no fewer than 6 authenticated 


\section{THE BRITISH JOURNAL OF VENEREAL DISEASES}

cases occurring after injection with penicillin. It had occurred to him that among the large numbers of patients treated with intramuscular injections of bismuth, very few had had jaundice ; he could remember only one case in about 15 years. He knew that post-bismuth hepatitis used to be described in the old days as a rare complication, but he had not met with it. Yet within a comparatively short time he had met with 6 cases of post-penicillin jaundice. That raised in his mind a shadow of doubt as to whether there might not be still a directly toxic element in some of these cases. He desired to ask Maj. Laird whether or not he applied the same technique to his blood-taking as to his injections. He had little doubt that in blood-taking infection could be spread quite easily, and he thought that some of these cases of penicillin jaundice were due to the first collection of blood at the clinic. He was not quite clear for how long the syringes were boiled in Maj. Laird's technique.

\section{Maj. Laird replied that syringes were boiled for 20 minutes.}

Lt.-Col. Marshall said that the year 1943 was one in which hepatitis was rife. Either clinical or subclinical, it was encountered in nearly all the clinics in the country. The investigation in his clinic, at least, was complicated to some extent, after the introduction of the boiling technique of sterilization, by the fact that the standard method of treatment was also changed from longterm to rapid (20-day) arsenotherapy. The two changes had coincided. When the technique was altered the incidence of jaundice fell from 50 to 10 per cent, but whether this was due to the change in the method of treatment or to that of sterilization, he could not say. The position had been changed again by the introduction of penicillin. Like the President, he had seen a number of patients treated with penicillin alone in whom jaundice developed about 100 days after treatment. He had thought, as the President had done, that this might have been due to contamination at the time of the taking of blood samples at the beginning of treatment or, possibly, subsequently. During the past year he had been using a similar sterilization technique to that employed by Maj. Laird, although he feared that it was not quite so perfect; to date, out of 200 cases treated with penicillin and arsenoxide, in only 2 had jaundice developed so far. He agreed that the most important factor in the so-called post-arsphenamine jaundice was the introduction of an infective agent by means of the syringe. Therefore, the penicillin technique should be accompanied by the same care in sterilization as was necessary in other treatment schemes.

Sg. L. E. M. Darmady said that for the past 3 years he had been in charge of a jaundice unit and that he had analysed the possible cases of syringe transmission. It had been found sometimes to be extremely difficult to get the history of injection at the relative period, but by means of a careful questionnaire certain facts had been established. Up to June 1945, out of 184 cases, 34 patients had a relevant history of having had injections. These were of different types, and since then almost 150 new cases had been admitted, of which the same proportion showed that history.

He desired to take up Maj. Laird at certain points. On the question of boiling it had been stated by some authors that 5 minutes were quite sufficient for sterilization. His unit had followed up 30 cases in which Pentothal had been given in a theatre doing " cold" surgery, and there had been 2 cases of what they had assumed to be syringe-transmitted jaundice. A careful technique had been followed and the syringe boiled for 20 minutes. It was believed that now that sterilized syringes had been introduced into the theatres the incidence of jaundice had been cut down, but the question of killing by boiling was one on which more work was needed

Col. L. W. Harrison said that it was important to consider the possibility of simplifying the technique. It seemed to him that one should concentrate on the essentials. There were certain vulnerable parts of a syringe which should not be touched by the fingers-the nozzle, plunger, and so forth-and it should be possible to assemble syringes largely through the medium of sterile forceps. If that principle were observed, a great deal of danger would be avoided very simply.

He recalled that, during World War I, 11 cases (9 fatal) of malignant malaria occurred at a military hospital in Ireland owing ta infection through the medium of the apparatus for administration of " 606 " (arsphenamine). It was supposed that the contamination occurred through the blood, which was always allowed to run back into the last section of the tubing, this including a glass window, so as to verify that the needle was properly within the vein. It seemed to be strange that this should happen because, after the contamination with blood, something like 250 cubic centimetres of the solution ran through that section into the patient's vein, and one would have thought that that would be sufficient to clear the section of blood cells. In order to see what happened, Col. Harrison had filled such a section with blood and then run through it 240 centimetres of saline solution from a " 606 " infusion apparatus before counting the cells in the next 10 cubic centimetres. The number in this 10 cubic centimetres was 100,000 . That showed how difficult it was to rid apparatus of blood.

Dr. C. H. Wilkie, after thanking Maj. Laird for his very convincing address, added a few remarks on what had happened at Leicester, where they were not fortunate enough to have so large a staff as Maj. Laird had had. Indeed, they worked a large clinic, with an attendance of anything from 40 to 70 patients a day, with 2 medical officers, one senior orderly and one senior male nurse in session at once. Their jaundice cases were very few, but one of their 


\section{PREVENTION OF SYRINGE-TRANSMITTED HEPATITIS}

difficulties was the need for better syringes and better facilities for sterilization. He had been told that he would have to take only one type of syringe and would be limited to a few of those. They had to manage as well as they could. The fact that their cases of jaundice were very few could be attributed in part to the other fact that all blood samples were taken with the needle only. That practice had been in force for many years. Another possible cause for the low rate of incidence of jaundice was that - even when one doctor was giving injections and only one orderly was assisting him-they were very strict as to the use of antiseptics between individual cases. The syringes were sterilized by boiling at the beginning of the session. In a similar clinic at Loughborough, which had been open now for two years, they had not had any case of jaundice ; there he was working.with only one medical officer and one senior male nurse. Jaundice had not developed in any of their own cases, although they had had patients coming in with jaundice contracted elsewhere.

Dr. F. W. Jacobson said that he had been impressed by the very great incidence of jaundice following arsenical treatment when he took over venereal diseases wards in 1944 in an Indian General Hospital in Bengal, and later at a Base Hospital of the 14th Army in Assam. There was a shortage of syringes and a good deal of the organization for treating big numbers of inpatients and out-patients had to be improvised. As he had to cope with up to 200 soldiers as out-patients on one afternoon, a way had to be found to eliminate the possible transfer of a hepatophilic virus through the use of the two or three then available syringes. Repeated sterilization by boiling was naturally out of the question in the prevailing circumstances. The following routine was worked out. Syringes were sterilized before the session started ; the needles were cleaned after use and boiled each time. The syringes and needles were cleaned after use by means of sterile distilled water and not of a saline solution. The difference was that distilled water produced immediate haemolysis and thus allowed a better mechanical cleaning of the syringes than did a saline solution, which did not destroy erythrocytes. After the distilled water cleaning, the syringes were cleaned with mercuric chloride $(1$ in 1,000$)$ or with oxycyanide of mercury $(1$ in 4,000). The mercury solution was then removed by washing with spirit and the spirit washed off with distilled water before the syringes were charged with neoarsphenamine for the next patient. Gallipots containing distilled water, mercury solution, spirit, and distilled water, respectively, were placed in one row and the whole process of washing out the syringe with the different solutions was completed in under one minute. After some weeks no more cases of jaundice were seen. This system worked very well later when introduced in Shillong and, after September 1944, in Ceylon; in the last-mentioned unit not a single case of jaundice had had to be reported up to the time that Dr. Jacobson left Ceylon in the spring of 1945.

Sg. C. Lloyd Jones said that, from June 1944 to the present time, over 600 cases of gonorrhoea had been treated with penicillin in his clinic and that in the same period of time 500 cases of syphilis had been treated with penicillin ; these were treated by both intravenous and intramuscular methods. In all these syphilis cases an average of over 10 blood samples were taken for Wassermann control daily in each case, and no occurrence of jaundice had been reported in any of the above cases.

Dr. W. N. Mascall said that in his clinic they were trying the use of syringes which had been dry-sterilized for a period of an hour at a temperature of $110^{\circ} \mathrm{C}$. The syringes were also washed in a solution of soda once every week. A separate syringe was kept for each patient. Nevertheless, they were still getting a certain percentage of jaundice. He could not help feeling that this was accounted for to a certain extent by damage due to the disease itself, to a certain extent by the toxic influence of arsphenamine, and to a certain extent by infection. As a routine, however, his clinic was still using spirit for sterilization. It had been pointed out that, if spirit were used, a certain dilution with water was more efficient than was absolutely pure alcohol. Some years ago they used to take blood samples by the needle and tube method and he recalled that they did not find any reduction in the jaundice rate.

He had hoped that Maj. Laird would say something about the seasonal incidence of jaundice. Cases were seen mainly at those periods of the year in which there was a considerable amount of ordinary infective jaundice about. The amount of jaundice seen in the armed Forces was, from the figures given, considerably larger than had been the experience in civil practice. The reverse might have been expected, as, on the whole, members of the Forces were better fed and fitter than were those of the civil population. If all these precautions had to be taken, he thought that separate clinics would have to be instituted for the treatment of syphilis alone. In a busy clinic, in which both gonorrhoea and syphilis were being treated, it would be impossible to go through all the regimentation suggested.

Dr. David Erskine said that Maj. Laird had made out a very strong case for the syringe transmission of jaundice. His own experience did not appear to agree with these findings. Working in a mixed clinic during the recent war, he had treated male and female service patients and civilians in one session and had used 6 syringes continuously and without boiling between injections; the incidence of jaundice had been almost entirely in the army cases, with very few cases in the Royal Air Force and only one or two cases among civilians. If virus transmission were the only explanation, why did the army cases suffer a higher incidence of jaundice? He also considered that it was irrelevant to compare the incidence of jaundice in 1943 with that in 1944 or at the present time. Even without employing the complicated technique which Maj. Laird 
had described, all clinics were now experiencing less jaundice than in 1943, so that the present improved position which he had experienced was probably not wholly due to the new technique employed.

Dr. R. Marinkovitch said that when he was in Salford he had investigated all syphilitic patients attending the Salford clinic during a five-year period (1928-1933, inclusive). In that time there were 170 cases of jaundice among syphilitics ( 7 per cent of the cases treated). During the same period the incidence of jaundice among gonorrhoea patients and those not infected with venereal disease was under 3 per cent. Generally speaking, jaundice appeared 3 months after the first injection of arsenobenzol (arsphenamine). The majority of cases received more arsenobenzol after jaundice than before, and only 2 patients had jaundice twice. After the year 1933, the dosage of arsenobenzol was increased and the incidence of jaundice rose, but never to more than 12 per cent. He had been surprised to see such an increase of jaundice among members of the armed Forces. Whilst in Nottingham he had found a lower rate of jaundice among syphilitics than in Salford; in fact it was under 5 per cent. The only difference in Nottingham was that arsenobenzol was given once weekly and that special syringes were used for bloodtaking. He was strongly of the opinion that there were a few cases of jaundice caused by arsenobenzol and that usually exfoliating dermatitis eventually developed in those cases. Although he appreciated the excellent work done by Maj. Laird, he thought that it would not be easy to carry out his elaborate procedure in an ordinary clinic, as additional medical staff and extension of premises would be necessary.

Dr. David Nabarro was interested in the cases in children. He had had a clinic at Great Ormond Street for more than 20 years, but he did not think that he could recall as many as 5 cases of jaundice occurring there. He gave large doses and sometimes the treatment went on for 3 or 4 years. At the same time he used to treat the mothers. He always boiled his syringes. He used to bring 3 or 4 syringes and half a dozen needles to the clinic. He took blood samples with the same syringes, which were washed in running water and sterilized, and were put out on a sterile towel for his nurse to assemble. Whether or not the explanation was that children were not so susceptible to jaundice, the fact remained that in those 20 years or more he had only about 5 cases.

There were two questions which he desired to ask of Maj. Laird. First, where did the taking of the blood for the Wassermann come in ? Secondly, at what strength did he use spirit ? It would be remembered that, in the recently published Medical Research Council's War Memorandum No. 15, it was stated, on p. 19, that the optimal concentration of alcohol for sterilizing purposes was about 70-75 per cent, which disinfected in 0.7 minute, whereas 100 per cent concentration was said to take more than 7 days.

Dr. MacGregor said that one of the speakers had referred to the occurrence of jaundice in patients who had been anaesthetized with Penthothal, and had also suggested that even 20 minutes' boiling of the syringe was not sufficient to sterilize it. They had to consider not only what happened to the syringe in the sterilizer but what happened afterwards. He had seen many anaesthetists giving Pentothal and had noticed the non-observance of the principles of surgical cleanliness. His own experience suggested to him that surgical cleanliness, as taught in the theatre, was really what was required.

Dr. Teeuwen said that in 6 years at Swindon he had seen 3 cases of jaundice, all of them in patients from the Forces. He was accustomed to use the same syringes for a number of patients. After use they were first cleansed in water by filling and emptying them several times by means of the plunger, then washed in running water, and afterwards put into the sterilizer before re-use. He had not had a single case of jaundice among civilians.

Maj. Laird, in reply, said that the prevention of jaundice might constitute an easier problem than answering all the points which had been raised in the discussion. The President had asked for further information regarding the venepuncture technique used by him. Out of the 167 cases which were specially followed up, some 60 were made the subject of a particular investigation; in these 60 cases blood had been collected by means of a syringe and naturally the full precautions of the technique were observed. In the other 107 cases the blood samples were taken with a needle and tube by Special Treatment Orderlies working in a different part of the same theatre. In regard to those 167 cases, at least, venepuncture probably did not play an important part. From the records of the civil clinic which he had mentioned, he had been able to study the facts in. relation to hepatitis in cases in which blood tests had been taken in the years 1941-1943 inclusive. Speaking of civil patients only and from memory, there were some 75 cases of jaundice in syphilitics. For the same three-year period he had been able to study records of gonorrhoea cases, all of which had a Wassermann test done on their first attendance; these were cases which had had a full follow up with final tests, the minimum period being 3 months. He had records of 250-300 patients, and in not one of them had jaundice developed, in spite of the fact that the patients were having their blood taken with syringes and that they were mixed up with the syphilitic cases. Therefore, although in theory he agreed as to the possibilities of infection through venepuncture, experience seemed to suggest that they were minimal. Concerning haematoma following the valve technique, it had not been a problem in his experience.

Col. Marshall had said that he was handicapped in drawing any conclusions as to the cause 
of the reduction in jaundice because there were at least two factors which changed at the same time. Maj. Laird's own investigation was planned specifically to prove or disprove the possibilities of syringe transmission, and therefore the investigators were careful to reproduce as far as possible the conditions obtaining in 1943. Hence they retained the same drugs in the same dosage. He thought that it was important to realize that jaundice was, on occasion, an epidemic disease quite apart from the use of syringes. If a large number of patients were being seen, particularly in a hospital, it would not be surprising if syphilitic cases with epidemic infective hepatitis were encountered. There was no claim made by him that the technique which he had described would guarantee to any patient immunity from infective hepatitis, although he would not get the jaundice through syringe transmission.

Concerning the period for boiling, Maj. Laird and his co-workers had chosen 20 minutes because of the declaration by certain authorities that 10 minutes' boiling was not adequate. So little was known about the viruses and their sensitiveness to either antiseptics or sterilization by, heat, that it was much better to err on the safe side. His own experience indicated that 20 minutes' boiling was effective.

Col. Harrison had wisely mentioned the possibilities of simplification, which was desirable. He feared that he had given the impression that his technique was complicated and time-consuming. In practice, however, with people who knew the technique and with patients instructed from the beginning and automatically going through their movements, the technique was not more time-consuming and not more complicated or difficult than was any less satisfactory one. He was himself considering what simplification could be introduced without sacrificing any of the essential precautions. He considered that a technique should be used in which the whole work could be done by one person, if necessary, with complete safety, provided that a sufficiently large number of syringes were available at the beginning. If one began with such a stock of sterile syringes and needles, and simply took up the sterile needle and syringe and charged it (incorporating as far as possible Col. Harrison's suggestion for handling with forceps), he would be inclined to say that one individual could carry it out, observing the same principles. If one orderly were available, a better method would be to leave him to charge the syringe, so that he never became contaminated, the medical officer giving the injection and then laying the syringe in cold water.

He had been interested to hear Col. Harrison's experiment in washing out the glass windowtube and needle which were formerly used in the administration of " 606 ," The whole account of the Portobello incident made fascinating reading; it was to be found in the second report of the Salvarsan Committee. The latter also included an account of a fairly large outbreak of hepatitis which occurred at a military hospital during World War I, and he would respectfully suggest that what was described was almost certainly an outbreak of syringe-transmitted hepatitis.

Dr. Wilkie had spoken about his experiences in Leicester and the official attitude to a request for further syringes. He would like to dispel any illusions that the Army was over-generous. He, at Colchester, had had two syringes, and it was not until it was suggested to a very high authority that, unless the syringes were produced, no responsibility could be accepted for the occurrence of hepatitis, that the official mind changed. He was firmly resolved that if any civil authority took a parsimonious attitude on the question he would adopt the same tactics.

Sg. C. Lloyd Jones had said that he had had no cases of hepatitis in a large series of penicillintreated cases, both gonorrhoea and syphilis. How long was the follow-up period ? Because of the long incubation period of jaundice the follow-up must be prolonged. He had been able to follow up his own cases only as a result of a tremendous amount of clerical work and of the cooperation of colleagues. No conclusions should be drawn without a follow-up of a large series of cases over a minimum period of 6 months.

Dr. Mascall had asked about seasonal incidence. Among the 44 cases which came in there was no observable seasonal incidence. There was no reason why syringe-transmission hepatitis should have such an incidence, except that the conditions necessary for it would depend upon an epidemic of infective hepatitis in the population at large.

Dr. Erskine and he had discussed the problem of incidence before in the Society's meetings. He thought that the difficulty was the differing rate of incidence of jaundice between civilians and the patients from the armed Forces attending the same civil clinic. He appreciated Dr. Erskine's point because he had been in the same position himself in 1943, but he thought that one explanation might be that the civil patients were probably more static than were those from the Forces. The patient who moved from one clinic to another with considerable rapidity had more chance of becoming infected by syringe transmission than had the patient who received all his injections in a clinic the rate of jaundice in which was low, and in which reasonable precautions were taken. That point also explained partly the lower incidence in the Royal Air Force ; the numbers dealt with were smaller, the personnel was more static, and prior to 1944 the technique in the Royal Air Force was certainly superior to that available in the army centres.

Dr. Marincovitch had interested him greatly with his remarks about the Salford clinic cases. He thought that the total number of arsenical injections was increased from one or two to three weekly, and it was reasonable to suppose that, if that were done in a clinic in which hepatitis was occurring, the risk of being infected was correspondingly increased. He had certain data which indicated that in two series of cases - one treated with weekly injections of neoarsphenamine and the other with twice-weekly injections of Mapharside-the incidence of arsenical jaundice was probably identical, but that in the second series hepatitis developed a little sooner because the cases were receiving twice as many injections.

Dr. Nabarro had spoken of his experience with children and had asked him two specific 
questions. As to whether children might be less susceptible than adults to hepatitis, Maj. Laird would have thought the position to be the reverse. It was true to say of epidemic infective hepatitis that it was a disease of children and young adolescents, and if that had any bearing on jaundice in syphilitic children, he would suppose that they were more susceptible to hepatitis than was the adult. In the children's clinic presumably a considerable proportion of the arsenical injections were intramuscular rather than intravenous. It was Dr. Nabarro's clinic and his views that he had had in mind when he said that jaundice was relatively rare in the treatment of children, and for that very reason.

Dr. Teeuwen's observations underlined what Maj. Laird had said about the nomadic patient's additional risk of syringe-transmitted infection. The whole matter of syringe transmission was rather fortuitous. It was possible to use an incompetent syringe technique perfectly satisfactorily, without any jaundice at all, until such time as infection was introduced, and then, if the precautions against its spread were not adequate, the trouble might start. From the records of the civil clinic about which he had spoken he had obtained a curve showing the percentage incidence of jaundice and of arsenical dermatitis for every year from 1918 to 1944 . The curve for dermatitis was a fairly steady one and was about 3-6 per cent ; there was almost no year in which dermatitis failed to occur. The jaundice curve was entirely different. There was no case of jaundice in that clinic up to 1924, in which year there were a few isolated cases; after that it was free of jaundice up to 1932, when there was a very mild outbreak in which he could find no evidence of case-to-case transmission, and which he thought corresponded to a local epidemic of infective hepatitis. In 1939 there were about 6 cases ; in 1940 there was no case ; at the end of 1941 two cases from the Forces came in and jaundice developed after a few injections; obviously these patients had been infected from outside. From then onwards there was a steady building up of cases in that clinic until sterilization by heat was introduced ; 3 months later jaundice disappeared from the clinic. Therefore one had to bear in mind the conditions which obtained before syringe transmission was introduced; if that were done it would be easier to understand certain data which appeared to clash with the theory of syringe transmission.

\section{ANNOTATION}

\section{THE ONE-MAN CLINIC*}

It might be that this contribution to the discussion of the able paper by Dr. Erskine ought to be prefaced by an apology, because, three years ago, when I was appointed as temporary Venereal Diseases Officer to the local clinic, I had few qualifications other than a keen desire to give the best possible service to the patients. As this clinic is on the periphery of the Venereal Diseases Service, some account of my impressions and difficulties may be of interest both to those who are placed in a similar position and to those who are more fortunate and who work in the acknowledged centres and large venereal diseases clinics.

Venereal disease work in a small town presents its own peculiar difficulties, especially when the clinic is held only once a week. The first difficulty which I encountered was that, during the hours of my clinic, all work in a neighbouring aircraft factory appeared to be suspended and the girls there used to watch, from the windows which overlooked the entrance, the patients going in and out of the clinic. This complication necessitated an interview with the ever helpful County Medical Officer, which resulted in a screen being erected to provide privacy for the attending patients. Later, a rise in the production curve of the factory was noted!

At this time I was able to engage as nurse-almoner a lady who was interested in the social aspect of the work. We agreed that in a small town a common waiting room is a form of torture chamber that should not be endured. Several other rooms were used for the people to wait in and; with common sense and care, the present premises became quite adaptable to the purpose of shielding the more sensitive patients, so that they were able to continue their treatment with a reasonable prospect of privacy. As a result of my experience, I would say that without a tactful nurse-almoner and adequate waiting rooms no clinic can work efficiently in a small town.

* The above annotation is a late contribution made by its author to the Discussion following Dr. D. Erskine's paper, "Difficulties in the successful treatment of the venereal disease patient", read on the 27th January 1945, and published in the June 1945 number of the Journal. 